\title{
Perceptions of Emotional Abuse with Respect to Depression, Anxiety and Low Self-Esteem among Pakistani Women from Low Income Families
}

\author{
Dr. Mona Aeysha Khalid \\ Assistant Professor, Kinnaird College For Women, Lahore \\ Email:mei3na4@gmail.com
}

Doi:10.5901/mjss.2015.v6n4s2p223

\begin{abstract}
In this paper, the implications related to emotional and psychological abuse lasted for a long time have been discussed with respect to the particular patriarchal society of Pakistan. The data has been collected through interviews, observations, and surveys from the randomly selected participants. The results indicate that the abuse not only damages the person's (being abused) self worth, self esteem, self respect, identity, self image and self understanding rather destroys the construction of the whole family where kids are especially at risk for later emotional and psychological disorders. Abusers in most of the cases are not aware of their behavior's worst implications; as no one dares to remind them of their abusive attitude. Thus, families trapped in such traumas often go unnoticed while promoting abusive emotions/perceptual information to the coming generations, through their biased beliefs, gender based baseless sayings, and fake spiritual knowledge in the name of religion, culture and norms.
\end{abstract}

Keywords: abusive relationship, domestic violence, gender discrimination, male dominated society, gender biased culture.

\section{Introduction}

Abuse is very much neglected term in the literature of domestic violence and criminal acts since long. For many centuries, people did not even comprehend the concept alone, for being so much complicated and personal to discuss and explore in concrete terms. However, in this century abuse has gained much attention due to wide spreading physical violence among families based on long term emotional abuse and women almost twice as likely to be victims of partner violence as men (see the web page for more info http://www.apa.org/pi/women/programs/violence/partner.aspx) . There are many kinds of abuse found in the literature: verbal abuse, physical abuse, child abuse, intimate abuse, domestic abuse, emotional abuse, psychological abuse, substance abuse, elderly abuse and abuse in the workplace. In this paper, we will focus on intimate partner abuse (male partner abuse in particular) that put the women in the vicious circle of depression, anxiety and stressful episodes of guilt, fear, doubt and self criticism.

In the cultures where gender discrimination is prevailing at a large level, men are usually considered as a symbol of power, honor, esteem, prestige and the leader in almost all affairs of life. They are no more permitted to act like a child or express their feelings to get some relief from their emotional outburst. That is why they seek dominance and control in their community, society and even in their family life through negative beliefs and irrational commands. They find it a way of expressing their selves, fulfilling their duty and rather a way of gratification through realizing their partners that they are inferior to them in various ways and subject to obey them at all cost.

Mills (2003) has discussed various reasons for the person being violent and aggressive in domestic life. To him, some violent acts are due to biological factors; some are due to brain injuries; while others could be due to central nervous system's ability to react the aggression in the environment. However, in most of the cases, people are prone to violent acts in the environment that flourishes/supports the abusive values and beliefs in general. Especially in intimate relationships, abuse is more related to environmental influences than biological factors.

In this paper, intimate partner abuses, with respect to its implications within the specific culture of Pakistan have been discussed. It will explore new angles to see the situation at present and make the people (victims and abusers) aware of their current (abusive) and detrimental situation. For others (non abusers and non victims) it will provide a rich data to support the victims and alarm the abusers as well for the worst possible outcomes that they are more likely to face in future due to their continuous abuse. It will also establish a theory for the new researchers to further analyze the information in the light of quantitative and qualitative data and save the nation from abusive relationships. 


\section{Research Design}

The word, ' abuse' is not very common in the typical traditional society of Pakistan. Mostly people do not recognize its meanings in their own language. When we inquired them, they were rarely able to comprehend the real meanings of abuse and its implications. Even though they are educated in such subjects; they are hardly ever ready to inform us about their personal abuse. It is beyond their comprehension that they provide some feedback to a researcher who wants to gather some of the information regarding abuse and especially their personal abuse. They, especially women are so much frightened that they could not convey their true feelings to outsiders including us. In such cases, we need to observe the people while keeping in mind the real purposes of the study and the related benefits for all of us being a part of common culture and heritage. We interviewed about 30 women from time to time and assessed their family position through a thorough observation and detailed analysis of the information got from their close relatives and friends. The observation lasted through many years and is based on factual traumas that those women were suffering from. In societies where male domination and gender bias are on the top level; one can only think of collecting data through observation as the real information would never be revealed by the subjects due to their unknown fear and high anxiety level. Moreover, in Pakistan, generally people are very much conservative, apprehensive, reluctant, hesitant and illiterate enough to provide the true information about their lives to the outsiders. Especially when one is being emotionally and psychologically abused on daily bases, he/she would not be able to reflect truly in front of strange researchers. Therefore a longitudinal study based on observation and collection of related facts and figures, was carried out in order to shed the light on the subject, the abused women's lives, their sufferings, low self esteem, depression, anxiety and other related risk factors.

\section{Literature Review}

What is abuse? It is very important to understand the true meanings of abuse in order to derive new meanings and associations with respect to emotionally and psychologically abused women in Pakistan. Emotional abuse, according to Engel Beverly (2002) can be defined as, " any nonphysical behavior that is designed to control, intimidate, subjugate, demean, punish, or isolate another person through the use of degradation, humiliation, or fear. Emotionally abusive behavior ranges from verbal abuse (belittling, berating, constant criticism) to more subtle tactics like intimidation, manipulation, and refusal to be pleased". It will also include domination and control, accusing and blaming, trivial and unreasonable demands or expectations, emotional distancing, isolation, disapproving, contemptuous or condescending looks, sulking and pouting, accusation, threats of abandonment- physical or emotional, and many other subtle forms of negative behavior along with negative attitude. Although each relationship suffers from some kind of abuse at some point in life; yet the emotional and psychological abuse is specifically diagnosed among women if the abuse is continuous, remains for years and never settles down (Chang, 1996).

Emotional abuse is the common part of all kinds of domestic violence which includes physical, sexual, emotional and economic abuse. In this paper, being emotionally abused have been interchangeably used with other similar terms like "intimate partner abuse", "spouse abuse", "domestic abuse", " marital abuse", "partner abuse", "battering", "financial abuse", "women abuse", "mate abuse", " marital assault" and "dysfunctional relationship"(McCue Laird, 2008; Cutler \& Zapf,2015)

In the patriarchal cultures, masculinity is usually taken as a sign of honor, freedom, success, power and dominance. The male members in such cultures not only run the house financially rather act like the ultimate boss who would carry out all the decisions for all the members of the household and would not allow them to act freely as per their own wishes. Women (being daughters and wives) are especially ignored when it comes to give education, health, and freedom. Mostly educated, well matured and intelligent women are bound to answer their men for their trivial actions (decisions) in day to day life. On the similar grounds, people educate the same discriminatory beliefs to their daughters and encourage discrimination indirectly. There could be several beliefs/thoughts manipulating in the background to make the women understand their low status, weak position, less worthiness, and about their valueless role/share in the society overall.

Although many countries have passed the laws to protect the victims from the perpetrators, yet these laws are neither implemented nor regulated. It is to some extent due to the universal belief that domestic abuse is a private matter. In almost all developing cultures of the world, unspoken traditions, norms and values dictate the violence, abuses, and assaults of many shapes against women (McCue Laird, 2008; Bryant-Davis, 2010). Although religion is taken as the source of peace, harmony and love in all over the world; yet in some cultures its teachings are being severely manipulated. Especially women are forced to live in abusive relationships, to become subservient to their masters 
(husbands), to remain in the torture and tolerate continuous painful experiences with patience. Thus, such faith based belief systems encourage abuse against women, violence at home and men's superiority over women in all matters of life directly or indirectly (Walker \& Others, 2015).

There are certain sayings, beliefs, and thoughts that generate a climate of superiority of men over women in the traditionally male dominated society of Pakistan. When women are brought up while digesting such phrases, they are mentally prepared to be abused. They look for their self respect and identity in the name of their husbands. They are not quite sure on how to be successful on their own, as they have already lost their self confidence at the very beginning and never get hope again. If they are married to a good human, they are the luckiest one; but if the other one is an abuser, they would have been trapped. Moreover, they would usually take years to understand that they are in an abusive relationship. Most of them would never be able to recognize /comprehend the philosophy behind their abusive relationships. Such women would always blame themselves for being less attractive, non cooperative, non-satisfying, and criticize themselves harshly for being the most annoying person for their husbands. They always curse themselves and feel guilt in return. They fear God for saying anything against their holy husbands.

On the other side, women who understand the matter fully, usually have no alternative to go back. They feel so much bound to live in an abusive relationship for the rest of their life. As there are fewer resources to utilize, no support groups to ask for help, and no family member to give a hand; women do not dare to leave the abusive relationship, almost at any stage of recognition. In short, the societal norms, family values, cultural traditions, common beliefs, religious education (in terms of interpretation), financial situation, kids education and other related factors collectively reassure them not to leave the abusive situation and stay there for as long as possible.

According to the Human Rights Commission (UN commission for Human Rights, 1996), in the 400 cases of domestic violence/abuse, reported in 1993, in the Punjab Province of Pakistan, half ended with the death of the wife (McCue, 2008, p. 79). Farris (2011) has pointed out several emotional excuses for the victims to stay in an abusive relationship for ages. To her, the woman remains in an abusive relationship due to the factors mentioned below:

a. She feels sorry for her husband and believes she could change the situation in future through hard work and patience.

b. She underestimates the situation by saying that he only hit every few months.

c. She blames herself and thinks she deserves it to be abused.

d. She is too scared to talk about it.

e. She thinks other people, even in her family would put all blame on her, if she asks for escape from her abuser.

f. She is being threatened by many ways so she could not dare to leave.

g. She fears being alone.

h. She stays due to religious or cultural constraints.

i. She stays for financial reasons, for children or for having no support system at all.

\section{Findings}

\subsection{Part 1}

When we surveyed about 100 house wives who were directly or indirectly part of abusive relationships, it appeared that many thoughts in the form of beliefs, sayings and quotations rested upon behind their attitude towards dealing with their abusive lifestyle. Women not only let the abusers abuse them (directly or indirectly); rather teach their kids to imitate them (the abusers) in the future. In brief, in the traditional, male dominant, patriarchal society of Pakistan, women are exposed to such teachings and beliefs asunder:

a. The woman should obey her husband if she wants to please God.

b. The husband's position is always superior to woman in all matters of life.

c. The woman should not say 'no' to sexual demand of her husband even in severe case of non-availability.

d. The women are supposed to make their husbands happy and cheerful.

e. It is the woman's duty to do all housework with no complain at all.

f. Successful woman does not talk against her husband.

g. Women should give priority to her husband and his family in all matters of life.

h. It is the first duty of a woman to take care of her husband.

i. The woman should not leave her husband's house and go out, without her husband's permission.

j. Good women are those who do not go against their husbands' will and wish.

k. Good woman should not eat food before her husband arrives home. 
I. Good women should eat either with her husband or after he finishes.

m. The woman should not call her husband's name.

n. The woman should replace her 'family name' from her father's name to her husband's name, after being married.

0. The women should not ask for sex from her intimate partner.

p. The women should not expect her partner to share household responsibilities with her.

q. The women should keep quiet when her partner is angry or violent (whether physically or emotionally)

r. The man can decide whether his wife will do a job or not.

s. The man can decide whether he wants to raise kids or not.

t. The man can decide how his wife will dress up. (Ultra modern or very conservative)

$u$. The man can decide whom to see and whom to ignore in the family.

v. The man can decide what to eat and what not to eat.

w. The man can decide about the future matters of his children (including education, professions, and marriages)

The list is never ending. However, people will not admit the credibility of most of the messages; but their women have been suffering in the silence of their abusive relationships for long.

\subsection{Part 2}

As a result of detailed interviews with 30 randomly selected low income families, observations and data collection procedures, in the particular patriarchal society of Pakistan, it came out that most women (95\%) were being emotionally and psychologically abused by their men (intimate partners) on a permanent basis.

It was concluded that:

a. More than 90 percent women felt they must get permission from their partner before making any trivial decision (it might be going to market for shopping).

b. More than 90 percent had no control over their partner's finance as well as over their own money. They just cannot spend money where they feel like to. It all depends on their partner's will and their luck where he is going to spend money!

c. Mostly, men are in the habit of passing negative comments /remarks on their partner, with severe arguments and criticism, whether it is related to their body, fashion, the domestic ability to do something or social ability to find a job outside.

d. Men are brought up to treat women as if they are inferior to them; and they continue treating them on similar grounds throughout their life. They always remind their partners about their inferiority, inability to succeed, and of their low status in society. Some remind them as if they are less attractive to them from time to time.

e. Men usually ridicule, dismiss and disregard women's opinion, thoughts, suggestions, and feelings in general.

f. Women who want to become financially independent are very much discouraged by their perpetrators. For them, it is very common thought that professional women are not good housewives or when a woman goes for a job; household affairs are largely neglected or it is not respectful for men to let their wives go out to earn a living.

g. In some cases, women are forced to go out for a job and then hand their whole pay to their in-laws or husbands. Such women have no right to spend their earnings as per their own wish.

h. In many cases, women were not allowed to see their parents as per their wish or need.

i. Women could not continue their education like men due to their domestic responsibilities, financial constraints, and their low status in society.

j. Women were not allowed to go for a job that was considered a man's property. For example: shop sellers, bus drivers, clerks, police jobs, business jobs, etc.

k. Women were not supposed to take part in sports, whether they like it or not. For a woman to find a career in any sport is very rare.

I. In some cases, women were not even allowed to go to see a male doctor, even in case of emergency.

$\mathrm{m}$. Women often feel the threat of divorce and kids' custody, in case of separating from their abusive partners.

n. People not only accept the male dominated behaviors in society; rather appreciate such males through verbal remarks. It is very common thought that men should control their wives to prove their masculinity.

0. Men who take care of their family members, are usually thought as weak, feminist, and of less confident personality types. As they are not real men! 


\section{Recommendations}

Evans (2012) has pointed out the worst implication in her book as the abuser continues with the abusive attitude within a family set up; children get the same poisonous teaching to apply in their adulthood. In addition, researchers found that " the children who were sexually abused have a 'fourfold increased lifetime risk for any psychiatric disorder and a threefold risk for substance abuse,"' (Mills, 2006, p. 88). Similarly, it is said that men who have experienced violence in their childhood are five to nine times more likely to behave abusively with their wives than others (Mills, 2006; Miriam, Patricia, Jocelyn \& others, 2003).

Wives on the other side, who are victims of a continuous emotional and psychological abuse from their partners, are usually diagnosed as patients with depression, stress, anxiety, OCD, hypertension, low self-esteem, and at risk for other psychological disorders. They are no more capable of handling their day to day affairs with confidence and dignity. They are very much reluctant and reserve in resuming their duties and giving a cheerful look overall. It is evident from the study (Watkins, 2014) that partner aggression (physical or emotional) has detrimental effects on women's physical and psychological health in terms of depression, anxiety, reduced self efficacy, increased shame and post traumatic stress disorders (Rhatigan \& others, 2011).

Keeping in view the above discussion, it is therefore recommended that it should be the state's responsibility to deal with such abusive relationships (whether they appear in public or in private); if they are unable to protect its citizens, especially women's lives from domestic/partner abuse (whether severe or minor) for any stated reason, they are indirectly involved in the process (Mc Cue, 2008), and they should be punished by the law in time along with the perpetrators.

In Pakistan, laws, regulatory agencies, judicial and police departments are worse; they need to be replaced by new standards, modern equipments and systems, modified rules with respect to laws and latest monitoring cells. This report is not designed to comprehend the legal issues related to the domestic abuse cases; however, it would suggest new researchers to cover this aspect as well in detail in the future endeavors.

For the general public, it is pertinent to understand the difference between custom and crime. When you are torturing someone, abusing someone's body and mind, degrading someone's personality, devaluing someone's skills and traits, underestimating the someone's abilities and characteristics, and controlling the someone's behavior through your abusive skills, harsh talk, offensive comments, rigid attitude, threats, severe jealousy, social pressure, physical power and cutting remarks; you are no more appreciating/encouraging your custom/norm/religion/culture/tradition/values or whatever you call it- you are a Criminal and your abuse is considered as a Crime. For that you deserve a severe punishment in return by law.

For the mothers of young children, it is highly recommended not to promote abuse through your negative beliefs and thoughts that, in one way or the other, would reflect from the adulthood behavior of your children (especially boys). You must understand the responsibility with respect to abusive relationships that your children might endorse it, if you are not teaching them the meanings of respect and honoring our better halves. Moreover, studies provide the evidence for a strong connection between partner abuse and child maltreatment (Whitaker \& Lutzker, 2009). So the mothers should understand the implications that their abusive relationship would bring and try to treat their children in the most normal and healthy way. It is worth considering that mothers should not teach their daughters about the male dominance and superiority over women, through their perceptions, thoughts, and beliefs.

For the victims of abuse, there is not much to say at least in the abusive environment of Pakistan. However, they are not destined to live in that situation forever. They might dare to say, 'No' to their abusive partners, show their unwillingness for irrational demands, argue in a positive way for not being treated fairly in the domestic life and can talk about their abuse to their friends, family members and people who work for such victims at national or international level. However, in this connection, several studies have already discussed the prevention measures in detail (GrahamBermann \& Edleson, 2001; Whitaker \& Lutzker, 2009) and have already presented a thorough framework to follow.

Though, it is never the abuser's fault to be abused in a certain way; however, they could adopt certain measures to prevent the abuse in their lives or at least to reduce the density of the abuse in the abusive relationships already established:

a. Women should identify the abuse in the first place and try to stop it there. When we ignore the abuse at the beginning while thinking it a trivial event of life, the more likely we are in the position to face such experiences again and again.

b. Women should set their limits, values, principles in advance before going into a relationship. When the other person is aware of our limitations already set; the more chances are, he would not dare to cross those limits.

c. Women should not pretend as if they are overly obedient, subject to be controlled, and too nice or caring for the other person in all circumstances. When women show such leisure attitude in the beginning of intimate 
relationships; it becomes hard for them to change the perception later on. Then the other person always takes it granted (if he/she is of abusive nature).

d. It is also recommended not to suffer alone. For the victims, it is no more a private matter of life. When they recognize their abusive relationship status, they must talk to their friends, family members or the societal groups who work for the victims at national or international level.

\section{References}

Bryant-Davis, Thema. (2010). Cultural considerations of trauma: physical, mental and social correlates of intimate partner violence exposure. Psychological Trauma: Theory, research, practice and policy. Vol 2 (4), 263-265.

Chang Valerie Nash. (1996). I Just Lost Myself: Psychological Abuse Of Women in Marriage. Westport, CT: Praeger.

Cutler, Brian L. (Ed); \& Zapf, Patricia A. (Ed). (2015). APA handbook of forensic psychology, Vol. 1. USA: American Psychological Association.

Evans Patricia.(2012). The Verbally Abusive Realationship. USA: Adams Media

Engel Beverly. (2002). The Emotionally Abusive Relationship. NJ: John Wiley \& Sons, INC.

Farris, Donna J. (2011). Why Women Stay In Abusive Relationships. E-Book edition.

Graham-Bermann, Sandra A. (Ed); Edleson, Jeffrey L. (Ed). (2001). Domestic violence in the lives of children: The Future of Research, Intervention and Social policy. Washington, DC, US: American Psychological Association. pp.(135-155).

McCue Margi Laird. (2008). Domestic Violence: A Reference Handbook. Second Edition. USA: ABC-CLIO, Inc.

Mills, Linda G. (2003). Insult to Injury: Rethinking Our Responses to Intimate Abuse. NJ: Princton University Press.

Miriam K. Dhrensaft and Patricia Cohen; Jocelyn Brown; Elizabeth Smailes, Henian Chen, and Jeffrey G. Johnson. (2003). Journal of consulting and Clinical Psychology. Vol. 71, No. 4, 741-753.

Rhatigan, Deborah L.; Shorey, Ryan C.; Nathanson, Alison M. The impact of posttraumatic symptoms on women's commitment to a hypothetical violent relationship: A path analytic test of posttraumatic stress, depression, shame, and self -efficacy on investment model factors. Psychological Trauma: Theory, Researsh , Practice and Policy, Vol 3(2), Jun 2011, 181-191.

Walker, Donald F. (Ed); Courtois, Christine A. (Ed); Aten, Jamie D.(Ed). (2015).Spiritually oriented psychotherapy for trauma. (pp.211231). Washington, DC,US: American Psychological Association

Watkins, Laura E.; Jaffe, Anna E.; Hoffman, Lesa; Gratz, Kim L.; Messman-Moore, Terri L.; Dililo, David. The longitudinal impact of intimate partner aggression and relationship status on women's physical health and depression symptoms. Journal of Family Psychology, Vol 28(5), Oct 2014, 655-665.

Whitaker, Daniel J.\& Lutzker John R. (2009). Preventing Partner Violence. USA: American Psychological Association.

http://www.apa.org/pi/women/programs/violence/partner.aspx 